\title{
On Religious Faith, Christianity, and the Foundation of Quantum Mechanics
}

\author{
I. S. Helland
}

\section{ABSTRACT}

On several levels, there is now a debate whether the concept of God can be made compatible with modern science. In an attempt to elucidate this debate, I give an account of my own experiences from writing a book on the foundation of quantum mechanics. In my opinion, one can give two independent arguments for the existence of God by taking as departure an epistemic (knowledge-based) interpretation of quantum theory. However, I also argue that any religious belief should be the result of an existential choice governed by each person's own context (history and culture). In particular, I give my account of Christianity as a religion connected to our western culture, how one as a scientist can relate to the relevant dogmas.

Published Online: January 26, 2022

ISSN: $2736-5514$

DOI: $10.24018 /$ ejtheology.2022.2.1.59

\section{S. Helland}

Department of Mathematics, University of Oslo, Norway.

(e-mail: ingeh@math.uio.no)

Keywords: Christ, Epistemic Interpretation, God, Quantum Theory

\section{INTRODUCTION}

As a point of departure, I give my own personal belief: I believe that there exists a God who created the world. However, I do not see myself as a simple creationist. I believe firmly in all established scientific laws, which implies that I believe in all established physical and biological theories.

Even so, I do think of us humans as created in God's image: We observe, make decisions and act. From my perspective, the details of this are related to the physical theories spelled out in Helland (2021), a book whose main content is somewhat technical. The essence of the book, seen from a philosophical point of view, is repeated below.

I believe that God acts within us, in the sense that He can influence our thoughts, our spoken words and our actions. But sadly enough, there are also evil forces within us, forces that also influence us. We have our free will, not a free will to choose our thoughts, but a free will to choose our actions and spoken words.

I believe that God can act within each of us, and that this may be true even for people who do not believe in God. And for people that do believe in God, their images of God vary greatly from person to person. In the language of quantum theory, which I will come back to below, we might say that different people have complementary images of God. This explains why different religions believing in a God exist, and it also explains the multitudes of churches within the Christian community. Here culture plays an important role.

In general: The choice of a religion is an existential choice. As any decision, it is governed by our own context: our personal history and the cultural values that we are grown up with.

The viewpoints described in this article have been under development both before, under and after the writing of Helland (2021). The article is partially an upgrading of the conference contribution Helland (2017).

\section{QUANTUM MECHANICS: THE EPISTEMIC INTERPRETATION}

The process behind Helland (2021) has been a long process. It started with the belief that, in some way, it should always be important to communicate between scientific cultures, and that such communication was limited between statisticians and people working with the foundation of quantum theory. With my own background, I felt that I could contribute something here, and it all has now ended up with a book where I describe both a possible common foundation for quantum theory and also basic statistical inference theory. The whole book is fairly technical and mathematical, but in the last chapter, I sketch a body of philosophical consequences. Some of these will be described in the next two sections. The book has now been revised, and this revised edition appeared in October last year. I do not regard this book to be perfect, but it gives my opinions on a large range of topics at the time when the book was written. One must have in mind, however, that opinions may change over time.

The starting point of Helland (2021) has been extremely simple. The common basis of statistics and 
quantum theory - as I have seen it - has been that of an epistemic process: A process to achieve knowledge. In the simplest case we have an e-variable (epistemic conceptual variable) $t$, asking a question to nature: 'What will $\mathrm{t}$ be if I measure it?' and obtaining an answer in terms of information about $\mathrm{t}$.

For nearly 100 years there has been a fierce discussion between theoretical physicists on how one should interpret quantum mechanics (QM); among other things, this discussion has as one of its themes: Is QM a theory about reality, or is it a theory about the knowledge we can obtain about reality? The last view is called epistemic or epistemological, and this view has received a fresh impetus during the last decade.

An essential part of the debate started between Albert Einstein and the Dane Niels Bohr in 1935, where Einstein, for philosophical reasons, took a very strong realist position. As a point of departure, my view has been epistemic, a view that is shared by many leading physicists today (see, for instance, the popular book Zeilinger (2010)). But I am currently also investigating consequences of my views upon possible ontological interpretations of at least some quantum states.

In statistical investigations, the e-variable $t$ is most often a continuous parameter, and the answer can be in terms of a confidence interval or a Bayesian credibility interval. (Never mind these technical terms; the important thing is that the answer is an interval.) In elementary quantum mechanics, $t$ is often discrete, and in a perfect measurement, we can obtain a definite answer: $\mathrm{t}=\mathrm{u}$.

Here one can first think of the two terms quantum mechanics and quantum theory as having the same meaning but note that quantum theory is a theory which also goes beyond physics: During the last few years, experiments in psychology, and theoretical discussions of decisions in psychology and in economics, show clearly that quantum theoretical considerations also can be made to play a role here; see Yukalov and Sornette (2014), Busemeyer and Bruza (2012) and Khrennikov (2010).

In quantum theory, we have what I call complementary e-variables. We can obtain information either about $t^{\wedge} \mathrm{a}$ or about $\mathrm{t}^{\wedge} \mathrm{b}$ by focusing upon the right questions to nature, but the vector $\left(\mathrm{t}^{\wedge} \mathrm{a}, \mathrm{t}^{\wedge} \mathrm{b}\right)$ is inaccessible. We cannot get full information about both variables at the same time. Examples of this abound in quantum physics, but it is extremely interesting that one now begins to find examples in sociology, in economics and in psychology.

Where do the probabilities in quantum theory come from? They are given by Born's formula, a formula which Max Born in 1954 got the Nobel prize for. In Helland (2021) I have a rather long derivation of Born's formula, starting from three premises: 1) A focused likelihood principle, which is a technical principle that can be derived from the general so-called likelihood principle in statistics. 2) An assumption of perfect rationality (not necessarily by the scientist herself; but she might have ideals that can be modeled by a superior rational being). 3) An assumption that the relevant e-variables are what I call maximally accessible.

Of course, this is not the full story, but it appears to me to be a very useful beginning for understanding quantum theory from assumptions that are related to the basic assumptions of statistical theory.

Note that the theme of this Section is limited to questions of the form 'What is t?', or more precisely, 'What will be the value of $t$ if we measure it?', where $t$ is some variable. Questions of this type are ubiquitous in natural science, while other types of questions might be more of interest, for instance, during research in psychology or social sciences.

The book Helland (2021) has recently been followed up by a few articles, where the resulting interpretation is compared to other interpretations of quantum mechanics, and other related questions are taken up. Science is an ongoing process.

\section{An EPISTEMIC ARGUMENT FOR A GOD}

To repeat the views of the previous section: The quantum formulation can at least as a first approximation be seen as having to do not with how nature is, but with our process of obtaining knowledge about nature. We focus on certain questions to nature and obtain answers to those focused questions. In Helland (2021) I indicate in different ways that essential elements of the quantum formulation can be derived logically by considering such a process - an epistemic process. The details of these arguments require some mathematics to derive.

Who is this 'we' who ask questions and obtain answers? It can be a single observer or a group of communicating observers. The epistemic process that this (these) observer(s) perform(s) can be related to statistical inference, and the quantity which he/she (they) ask questions about and obtain information on can be likened in some way to a statistical parameter. But it may be different, since it often concerns a single unit instead of a population of units. I have introduced a new term, e-variable, to cover both parameters in statistics and these single unit quantities. An e-variable can always be thought about as existing in the mind of an observer or in the joint minds of a group of communicating observers.

I claim that the e-variables are not hidden variables, but closely connected to the epistemic processes, the process of obtaining knowledge. Also: Doing inference also has to do with intuitive processes in the brain. The brain is no computer and cannot be simulated by any system of computers, so the epistemic 
process which lie in the foundation here, cannot be simulated by any system of classical computers.

Although essentially new arguments behind quantum mechanics are presented in Helland (2021), I still regard conventional quantum mechanics, based on abstract concepts related to what is called Hilbert space, as extremely useful when it comes to calculations. It is the point of departure for very much research today.

In the same way, the statistical culture, as it is described in Chapter 2 of Helland (2021) and far beyond that, has a vigorous development today. What I try to point out, is, that these two cultures may be seen to have a common basis in the concept of an epistemic process. Nevertheless, one can perhaps argue that neither quantum mechanics as a science nor mathematical statistics as science nor applied statistics as a tool in many empirical sciences would have developed as far as they have if some sort of a synthesis between the two cultures had been established from the beginning. If one has this view, it can be linked to the quantum mechanical concept of complementarity. Universality and creativity may be seen as complementary qualities.

The concept of complementarity is extremely important in Helland (2021). As a first application in the book, the concept of complementarity is connected to the process of obtaining knowledge, that is, the epistemic process. As a physical example, look at two complementary e-variables like the position and velocity of a particle. If we try to get exact knowledge of the velocity, it is impossible to get any information of the position, and vice versa. This can be made quantitative by Heisenberg's uncertainty relation.

But in a macroscopic setting, the concept of complementarity can also be connected to knowledge achievement, which, of course, is related to education.

Assume that a young student has been given a rather difficult task as homework. He decides that he has two goals with his work with this task: To get finished soon, and to find a good solution. These are complementary goals. If he is a clever student, the degree of complementarity may decrease.

Thus, the concept of complementarity can also be associated with human abilities. Humans observe, make decisions and act. Then also complementarity concept may also be related to our decisions and actions. Assume again that a student is to work on some given assignment. He can have his focus on satisfying teacher A or on satisfying teacher B in the decisions and actions he makes when working on the assignment. These can be complementary foci. The complementarity can be reduced if more time and concentration is devoted to the assignment.

Going back to the epistemic process situation, the basic feature of the approach in Helland (2021) was focusing: Ask a selected (maximal) focused question to nature and obtain a specific answer. From a given observer's point of view, this defines a state of nature.

The focus used in Helland (2021) is precise and formal. Informally, focusing is very often necessary in our daily life when we want to obtain knowledge before making decisions and acting from these decisions. We simply do not have the capacity to absorb all the knowledge from all the sources that we are confronted with.

An epistemic process, as used in Helland (2021), is a very wide concept. Every epistemic process involves decisions, a decision to ask a question and a decision to accept the answer. It is interesting to note that also the other assumptions made in Helland (2021) have informal analogues for humans making decisions.

It may also be interesting to speculate around the fact that something called the free will theorem follows from the assumptions of quantum mechanics. Humans are governed by their free will, and they are constantly confronted with other humans that are governed by their free will.

All these speculations, and indeed the whole idea of a purely epistemic foundation of quantum mechanics, make one a little uneasy, however. The universe was created 13.8 billion years ago, and physical laws, including quantum mechanics have presumably been valid since then. How can then everything be so tightly connected to the human observer?

A possible solution in the spirit of Helland (2021) is connected to the imagined observer and the 'perfectly rational' actor(s) that inspire him, both important concepts used in this book. To go into more details on the question on what these elements stand for, is again mere speculation, but at least all technical assumptions made in the book seem to be consistent with the assumption that there somehow exists a God. In fact, this also may provide a link to the ontic interpretation of quantum mechanics - that is, the interpretation that the laws of quantum mechanics have to do with real properties of the world.

A similar proposal was in due time made by the philosopher George Berkeley in order to avoid accusations of solipsism (the view that my mind forms a separate world that can observe the external world. My mind is the basis for all my actions.).

In fact, I share some ideas connected to a version of solipsism, but nevertheless, for several reasons, I have chosen to believe that there is a Creator of the universe, who during the creation also observed it. Then later this Creator is at each time able to observe, make decisions and act. He is perfectly rational.

I believe that we humans are created in His image, but we are imperfect. The last statement is obvious; the first may be argued for from the fact that we also are able to observe, make decisions and act. This is the basis for the idea of an epistemic process. 
With now a divine Creator entering the stage, this idea obtains a new dimension. If all idealized Heavenly observers agree on the result of their epistemic process, this result must be said to be an objective fact.

This gives us a simple tentative argument through the concept of an epistemic process, which was argued above to lie behind the formalism of quantum mechanics, to an ontic view of the world, to the view that any physical system, including the whole world, has a real existence. Technically, all this may be associated with what some physicists call the total wave function (state vector) for a given situation, and the relative state as perceived by an observer.

Unfortunately, a corresponding epistemic process carried out by human observers may, at least sometimes, be imperfect. Nevertheless, when all relevant observers agree on an observation, we can often be fairly sure that this is an objective fact. Such a conclusion is strengthened if the epistemic process leading to the conclusion is a scientific investigation.

The divine Creator may be called God. He is worshiped in different ways in different cultures and $\mathrm{He}$ is perceived in different ways by different groups of people. This can be explained by the fact that we humans only can have an imperfect image of God. It is also connected to the fact that we all have different contexts, also when making deep decisions. The concept of a context has played an important role in Helland (2021), it is important in any epistemic process and it is important for any process of making decisions.

From my perspective, the ultimate actor God must in some way be the same across all cultures, and $\mathrm{He}$ must be acting over and above what particular image each single person might have of Him or of aspects of Him.

At the outset, we know little about the goals behind the decisions made by God. My own conviction is related to Albert Einstein's saying: The Lord is subtle, but not malicious. It is also based upon the God who ends the play Brand of Henrik Ibsen: Deus caritatis; the God of love. Thus, there seems, in my opinion, to be a God who is good and wants the best for us humans. But in a world where we all have our free will, God is confronted with many complementary goals. On the one hand, He is almighty. On the other hand, He seems to meet logical impossibilities if He should do the best for absolutely all of us.

This argument is very simple, and I am in no way able to explain all the suffering in the world by such an argument. One might perhaps see some sort of an answer by indicating that suffering by certain people may give other people an opportunity to work out the best sides of themselves. But these are extremely difficult questions.

Another difficult question is whether faith, in some cases, may help people recover from an illness. This question is related to the placebo effect, an effect which several investigations have shown is very strong. Many Christians refer to examples where they have seen that prayer might help sick people. Sceptics argue that it is extremely dangerous to spread such a message. But not to be able to argue for the fact that a very positive effect of placebo might help some people, is also dangerous. Again, one ends up with the phenomenon that one here has an example of complementary points of view.

By all these speculations, I have been entering the realm of theology, which is not my specialty. But one can never stop wondering about the large and difficult questions. Some of the answers must remain open at this stage.

Thus, I value high very many aspects of religion. However, I have great difficulties with the attitude: 'We in our religious community are right. The others are wrong.'

I am strongly against any kind of fundamentalism. Extreme Muslims may become terrorists in the belief that they have the right religion. Israeli settlers occupy Palestinian land in the belief that they have the right religion. It is important to have an open mind towards the beliefs of other people, but such an open mind should also have its limitation. There are no simple solutions to the deep conflicts in this world.

In the same way, as I believe that there exists an ultimate God, I also believe that there in a very concrete sense is an ultimate science. It is very fruitful to do science in various scientific cultures, but there must be a logical way to understand the conclusions obtained in different cultures in a unified way. This is a personal conviction behind the work of the book Helland (2021), but the view may perhaps be generalized to other human activities.

At this point it is natural to stress that also science has its limitations. Science is not able to explain consciousness. Science is not able to grasp in any way the spiritual power behind a symphony by Ludvig von Beethoven, a painting of Pablo Picasso, the finding of theorems by Nils Henrik Abel or the finding of theories by Richard Feynman.

We all have a mind which cannot be scrutinized in detail by any scientific investigation, however far our knowledge of the brain is developed. Thus, there is a room for a dimension in life that goes beyond science, in my view, also a room for religion.

\section{An ARGUMENT FOR GOD CONNECTED to DECISIONS AND TO BORN's Formula}

We all go through our lives making repeated decisions in different contexts. These decisions are governed 
by our free will, but they may also be influenced by people that we look up to, who perhaps have done similar decisions before. In our childhood, the persons that form our basis are most often our parents, but later other ideals may take over. Human beings that suffer from a confused relation to their first ideals, may later have difficulties in making good decisions, and they may end up with having psychological problems. Much mental illnesses can be explained in this way.

As scientists, we also have ideals that we look up to. These may be personal, or they may be substantiated through certain well-defined principles.

In Helland (2021), I have a new argument connected to the derivation of Born's formula. This formula is the basis for all probability calculations in quantum mechanics, calculations connected to any experiment that can be imagined. In deriving this formula, I made the assumption that the experimentalist A, when posing a focused question to nature, may make his decisions inspired by an ideal $\mathrm{D}$, and that $\mathrm{D}$ is perfectly rational.

This may be regarded as a simplification. In reality, when making our decisions, we are influenced by a multitude of conscious or subconscious sources. In the above argument, all these sources are collected together in the superior actor $\mathrm{D}$. I assume that $\mathrm{D}$ has a positive influence on $\mathrm{A}$, positive with respect to the goal that A has, in this case, the question that A has chosen as the focus of his experiment, together with any question concerned with his interpretation of data.

It is very essential for the argument that $\mathrm{D}$ is perfectly rational. This assumption, or the very tentative alternative assumption that A himself can be seen as 'perfectly' rational, is made precise by using what is called a Dutch Book argument, a type of argument which is also used by other scientists working with the foundation of quantum mechanics.

From the point of view of the present article, this perfectly rational ideal has many of the attributes that one can associate with the concept of God. However, there is a difference: The above actor D is assumed to be limited to the process of achieving knowledge through experiments or measurements; usually one associates God also with something wider.

Let us look at the process of making decisions in some greater generality. People in different cultures make their decisions partly intuitively on the basis of cultural values. These values may have a historical origin, and they may also be related to religion. Christianity, Islam and Judaism are all founded upon the belief in a personal God. The believers act under the assumption that there is a God behind everything, and that God is perfect. They believe at the same time that He influences all human beings, also those who serve as ideals for others. In this sense, God may take the role as an ultimate ideal within the relevant culture.

A culture may always be looked upon as part of a man's context when making his decisions. At the outset, all human beings should be respected, and so also the context they have for making their choices. Hence it is a part of my philosophy that no culture should in principle be seen as definitely better than other cultures when it comes to inspiring people's decisions.

However, this tolerance has it limits; one of these is an ultimate respect for people's life. Extremists taking lives under the belief that their own culture is threatened by other cultures, should of course not in any way be accepted. But there are also other universal ethical rules that should be respected by everyone.

In essence, certain cultural values and more generally certain value-contexts for making decisions may be seen from a global point of view to be more satisfactory than other set of values, but this can only be determined by rational arguments. Hence communication between cultures is very important in our world as it is now. As a particular continuation of this statement, the book Helland (2021) in itself is written with the partial purpose of finding a common language with which one can communicate across scientific epistemic cultures.

\section{CAN One, In the Modern Western Culture, Argue For a Faith in Christ?}

Christianity has had a large influence on our western culture for many hundred years. Artistic expressions of any form in the past and even scientific reasoning in the past had often links to Christian histories, norms and beliefs. But in modern times more and more people have been alienated from all kinds of religion.

Many independent historical sources tell us in a quite convincing way that there lived a man called Jesus Christ in Judea around 2000 years ago, and that this was a quite extraordinary person. A crucial point as I see it, is whether or not we today can be able to look upon this person as divine, both God and human. Generations of western people have lived their whole life based on the simple belief that Jesus was God's son. The question I want to raise here is whether it is possible in our modern time to maintain such a belief.

In the gospel, according to John there are many fierce disputes between Jesus himself and the Jews. Jesus repeatedly said that his words about himself were inspired by God, but the Jews accused him of blasphemy. In some sense, a similar difference of opinion still exists between Judaists and Christians. In the language of Helland (2021) we here have to do with complementary world views. But this does not prevent each of us for trying to make up our own opinions. 
Was Jesus the perfect ideal that Christians claim Him to be?

Some clues may be seen from Jesus' teaching. As read from the 4 gospels, this teaching is quite radical, but there is no doubt that this teaching has had a positive influence on many good people during the centuries. Also today, our western societies must be said to be positively influenced by many Christian values.

But then, on the other hand, there are many good people who do not believe in God, and who reject the teaching of Christ. I am in no way able to see Christianity, as taught in the various churches, as the only way to salvation, whatever that means. "In my Father's house there are many rooms," said Christ.

Perhaps the central message of Christ is something that many of us can agree upon: The message of love. Love of God for those who believe in Him, and love of our neighbors.

Then what does love of God mean? "The kingdom of God is within us," said Jesus. So partly, as a first approach, I think it may mean to try to cultivate the good sides of ourselves.

It may also mean to act according to what we perceive as God's will. Jesus said that he had not come to turn down the laws of the Jewish bible, but to fulfil them. In particular, the 10 Commandments are good guidelines for all of us. Jesus also gave us other guidelines.

Next, it may mean to realize that we are not gods ourselves. This is a crucial issue, as I see it. At times I feel that some people may tend to act as if they were 'gods' in some sense. Then they first insist that their own opinions should dominate over all other people's opinions, and secondly, this point of departure in effect determines all their actions with other people. This is a sin that I see as quite serious, at least when it is connected to people that have some sort of negative power over others; in the extreme case, look at Hitler or Stalin.

Avoiding a tendency in such directions can at times be difficult, but a way to proceed is to think that we in any situation may have human ideals to look up to, other humans that maybe have gone through similar processes and found good solutions to questions that we struggle with, ourselves. In other cases, more abstract ideals will do the job. My point is that in any situation and with respect to any issue one should have in mind something or someone more superior than ourselves.

For people who do believe in the Christian God, the love of God must in addition mean something like: Remain in the faith that there is an almighty God who loves us and is able to help us being better humans. Finally, love of God, for those who do believe in him, means simply to worship Him.

But then, turn to the love of our neighbors. Who are our neighbors? Here Christ is extremely radical: We should even love our enemies. It is clear that love is not a feeling in this connection; it is a question of actions and of attitudes. In the teaching of Christ, as I see it, our decisions at all times should ideally be such that they are intended for the good of all people, at least for the people that we are in contact with at the moment that we make our decisions.

Some very good people might be able to live in such a way always, but for most of us I think this demand is impossible. We humans are far from perfect.

It is not at all easy to hold on to this extreme love in all possible aspects that we are confronted with. And it is very difficult to really live up to the requirements indicated above: The love of God and the love of all humans. One option may be to concentrate our love to our nearest, husband, wife, family and so on, but this may lead to a limitation.

As I see it, one might here have two ideas in our mind at the same time: Love means one thing together with our nearest group, a somewhat different thing when trying to generalize to all of mankind.

But how should our own group be regarded, and how should this group look upon itself? In my opinion, it is also important that such a group of people do not either act as if playing God. To give an extreme example again: 'Gott mitt uns' said the nazis in the 30s and 40s.

This should be contrasted to the good sides of the phenomenon that people seek together in groups. Humans are social as a starting point, and it is natural for all of us to act as social beings. The premise of Richard Dawkins (1976) that our genetic basis make us selfish when acting in societies, has bee countered by several authors, among others the Norwegian biologist Dag Hessen (2017). The last book discusses both positive and negative aspects of the human tendency to seek together in groups, but ends with a positive note connected to our need to find a meaning in life.

In a Christian context, people find together in congregations. This may in itself be positive, but the complementary negative side of it, is that some members of the congregation may act as if they are right in all questions. In certain instances, this may even imply that someone with a minority view on some questions is expelled from the congregation.

Another issue may be that some members feel that religious people, particularly people in the congregation, in some ways are better than people outside the congregation. All this is also a way of playing God, as I see it.

Parts of this reasoning may also be valid in other connections where people organize themselves together in some group. It should be clear that arguments of this type should not be taken as arguments against political, religious or social group activities, for instance. It should just be taken as an argument for openness 
towards the opinions of people outside the relevant group.

In all our endeavors, in all our attempts of making decisions, we may meet complementary goals. And as none of us are perfect, we may fail according to some norms in making our decisions, or we may fail in the process of coming up with a decision. On other questions we might fail to get engaged, even though the questions are important.

Could this always be related to the concept of sin? Should perhaps only some of these failures be called $\sin$ ? Neglecting important questions that have consequences for other people, for instance. In full generality, I frankly do not know the answers to these questions. But to some Christians, the sin-concept is important in such connections. This is understandable; however, I have personally a feeling that the sin-concept is over-tuned by many Christians.

As I see it, the only option for a believing Christian is to rely upon the central message of Christianity: Christ died for our sins.

What does it mean to believe in Christ? Here my opinion is that the Christian churches simply demand too much from us. Seemingly, we are required to believe in virgin birth, to believe that he walked on water, and not least, to believe in the resurrection, Christ's resurrection and in some way or other, our own resurrection. The church tends to teach about a resurrection in the flesh, which I myself see as very strange. Of course, all of this, or some of it, might reflect a deeper truth, but on these questions and with our own limitations, we can only rely upon our own inner voices, and what we learn from others, orally or by reading.

It may be of some importance what Jesus said about himself; see for instance Luke 10.22.: 'All things have been committed to me by my Father. No one knows who the Son is except the Father, and no one knows who the Father is except the Son and those to whom the Son chooses to reveal Him.'

Or in more radical terms, John 14.6: 'I am the way and the truth and the life. No one comes to the Father except through me.'

Jesus also said, when he was called 'good,' that only God was good. Furthermore, he at least once said that he did not know anything about the time of the doomsday; only God knew that. From this, one can, in my opinion, conclude that Jesus did not look upon himself as perfect in all respects.

I do believe that one can learn more about these issues by reading, for instance in the Bible, by introspection and perhaps by praying, or by talking to other people.

I can only say what is important to myself: Christ has with his words, say, the Sermons of the Mount and much else, given me positive inspiration. In particular, he has taught us how to pray to God. His Lord's Prayer is to me invaluable. At the same time, people having a strong Christian belief have also given me some inspiration, at least when it comes to questions related to religion.

But frankly, I have also been inspired greatly by other people, people without any religious belief.

At the outset, we know very little about our life after death. To many people, Christ's resurrection and the idea of an eternal life is the central message of Christianity. As I see it, one certainly can believe that we all have a soul in some sense, and that this soul - in a way that neither of us understand - can continue to live after death. But I have difficulties in believing in some 'resurrection in the body'.

The Bible has a very clear and simple message here; see, for instance, 1 . Corinthians $15,12-19$, which is extremely clear on this point: 'For if the dead are not raised, then Christ has not been raised either. And if Christ has not been raised, your faith is futile, you are still in your sins.' It even ends with 'If only for this life we have hope in Christ, we are to be pitied more than all men.'

Admittedly, one can find much in the writings of Paul that modern people have to disagree with. But this seems to be a very central part of Paul's own Christian faith, and in the ideas that he strongly wanted to get his followers to believe in. One of his arguments was that more than 500 people had seen Christ resurrected, many of them still living as he wrote about this.

A crucial point is that all this is written in the same letter as 1 . Corinthians 13, the praise of love, which I myself see as the essence of Christianity. So, in this spirit, let the three remain: Faith, hope and love. One might say that the idea of an eternal life for some people belongs to the domain of hope, but for other people this idea also has a strong element of faith attached to it. For me, this faith has been strengthened during the last years.

Finally, what should one say to people who seek a faith, but are not able to believe in any specific religious message? One possibility might be to appeal to the words of Mark 9, 24: 'I do believe; help me to overcome my disbelief.'

\section{CONCLUSIONS}

First, take the theological part of this article. Personally, I see God as greater than Christianity. And I see Christianity as greater that a set of dogmas claimed by the church.

In this cruel world, I mean that it is a blessing and a strength to have a conception of God in some sense or other, and from this to have a personal faith. At least we should all be able to unite in the common hope 
shared by Christians and beyond: A hope for peace on this earth and for mercy among us humans.

For the physics part of this article, I can only conclude that science is an ongoing process. After some problems are solved, new problems remain to be addressed. From my own approach to physics, it remains to clarify further possible relations to quantum field theory, to the standard model of particles, and to special and general relativity theory. All this belongs to the future.

\section{ACKNOWLEDGMENT}

I am grateful to Jan-Olav Henriksen for comments on an earlier version of parts of this article.

\section{REFERENCES}

Busemeyer, J. R., \& Bruza, P. (2012). Quantum models of cognition and decision.] Cambridge University Press, Cambridge.. ISBN 978-1-167-0199-1

Dawkins, R. (1976). The selfish gene. Oxford University Press, New York. ISBN 978-0-198-78860-7

Helland, I.S. (2017). The conception of God as seen from research on the foundation of quantum mechanics. Dialogo Journal 4 (1), 259-267.

Helland, I.S. (2021). Epistemic Processes. A Basis for Statistics and for Quantum Theory. Springer,.Cham, Switzerland. Revised edition. ISBN 978-3-030-8192-4

Hessen, D.O. (2017). (In Norwegian) Vi. Samarbeid - fra celle til samfunn. Cappelen Damm, Oslo. ISBN 978-82-02-52606-1

Khrennikov, A. (2010). Ubiquitous quantum structure. Berlin: Springer. ISBN 978-3-642-05100-5

Yukalov, V.I., \& Sornette, D. (2014). How brains make decisions. Springer Proceedings in Physics 150, $37--53$.

Zeilinger, A. (2010). Dance of the Photons. From Einstein to Quantum Teleportation. Farrar, Straus and Giroux, New York. ISBN 978-0-374-23966-4

Zwirn, H. (2016). The measurement problem: Decoherence and Convivial Solipsism. Found. Phys. 46, 635-667.

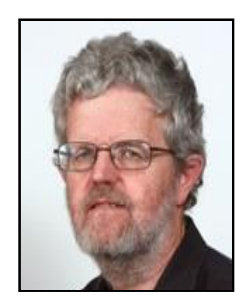

Inge S. Helland was born in Bergen, Norway in 1947. He was Cand. Real. at the University of Bergen in 1973 and Dr. Philos. at the University of Oslo in 1980. The major field was statistics.

He was University Fellow at the University of Bergen 1973-78, Associate Professor at The Norwegian University of Life Sciences 1973-83 and Full Professor at the same university 1983-96. From 1996 he was Professor of Mathematical Statistics at the University of Oslo until retirement in 2012. He has a long list of publications in several areas of pure and applied statistics, also some on the foundation of quantum mechanics.

Prof. Helland is a member of The Norwegian Statistical Association, The Bernoulli Society and The Institute of Mathematical Statistic. 